\title{
Protein production and secretion in an Aspergillus nidulans mutant impaired in glycosylation
}

\author{
Urszula Perlińska-Lenart ${ }^{1}$, Wiesław Kurzątkowski ${ }^{2}$, Piotr Janas ${ }^{3}$, Agnieszka
}

Kopińska $^{3}$, Grażyna Palamarczyk ${ }^{1}$ and Joanna S. Kruszewska ${ }^{1 凶}$

${ }^{1}$ Laboratory of Fungal Glycobiology, Institute of Biochemistry and Biophysics PAS, Warszawa, Poland; ${ }^{2}$ State Institute of Hygiene, Warszawa, Poland; ${ }^{3}$ Department of Food Technology and Storage, Agricultural University, Lublin, Poland

Received: 14 September, 2004; accepted: 18 January, 2005

Key words: glycosylation, protein secretion, dolichylphosphate mannose synthase, DPM1 gene, Aspergillus

\begin{abstract}
O-glycosylation has been considered a limiting factor in protein secretion in filamentous fungi. Overexpression of the yeast DPM1 gene encoding dolichylphosphate mannose synthase (DPMS) in an Aspergillus nidulans mutant (BWB26A) deficient in O-glycosylation caused an increase in the number of secretory vesicles and changes in protein secretion. However, the secretory proteins, primarily O-mannosylated glucoamylase and $\mathrm{N}$-glycosylated invertase, were mainly trapped in the periplasmic space. Different glycoforms of invertase were found insite the cells, in the periplasmic space and in the cultivation medium. Our data point to the importance of the cell wall as a barrier in protein secretion.
\end{abstract}

Elucidation of the regulatory mechanisms and limiting factors in O-glycosylation of secreted proteins is an important task, since the efficiency of protein secretion appears to be related to their O-glycosylation (Kubicek et al., 1987; Kruszewska et al., 1999; Agaphonov et al., 2001). It has been shown for Trichoderma reesei that inhibition of O-glycosylation, in

\footnotetext{
This work was partially financed by the Committee for Scientific Research, KBN, Poland, Grant 6P04B00621 to J.S.K. The financial support of the Centre for Excellence in Molecular Biotechnology, Warsaw, Poland, is also acknowledged.

${ }^{凶}$ Correspondence to: Joanna S. Kruszewska, Laboratory of Fungal Glycobiology, Institute of Biochemistry and Biophysics PAS, A. Pawińskiego 5a, 02-106 Warszawa, Poland; tel.: (48 22) 592 1209; fax: (48 22) 658 4636, e-mail: jsk@ibb.waw.pl
}

Abbreviations: AMM, Aspergillus minimal medium; DMP, dolichylphosphate mannose; DPMS, dolichylphosphate mannose synthase; GDPMan, guanosine 5'-diphospho-D-mannose. 
contrast to inhibition of N-glycosylation, blocked protein secretion (Kubicek et al., 1987). A similar effect was observed for a mutant of the yeast Hansenula polymorpha partially blocked in the production of guanosine 5'-diphospho-D-mannose (GDPMan), a primary sugar donor in protein $\mathrm{N}$ - and O-glycosylation (Agaphonov et al., 2001). In those studies secretion of two secretory proteins, i.e., the O-glycosylated chitinase and the $\mathrm{N}$-glycosylated invertase was compared in the parental strain and the opu24 mutant. Although less glycosylated, invertase was shown to be secreted without disturbances, in contrast to the underglycosylated chitinase which was secreted in small amounts. Clearly visible changes were also observed in the cell wall of the opu24 mutant resulting in increased sensitivity to zymolyase.

In our earlier study we identified some of the factors affecting protein secretion and activity of dolichylphosphate mannose synthase (DPMS), a key enzyme in O-glycosylation in T. reesei. Choline and Tween 80 , when added to the cultivation medium, stimulated secretion and, at the same time, elevated DPMS activity (Kruszewska et al., 1990). Moreover, overexpression of the yeast $D P M 1$ gene in $T$. reesei increased protein secretion of wild type glycosylated proteins up to seven-fold (Kruszewska et al., 1999). Significant changes were also observed in the ultrastructure of the mutant cell wall and some organelles. The cell wall of the $T$. reesei strain overexpressing DPM1 JSK97/3 had a flocculent structure as opposed to the compact cell wall of the parental strain. We reasoned that such a loose cell wall could be more permeable and simplify the flow of secreted proteins. Simultaneously, an increase in the number of mitochondria was also observed.

In this work we demonstrate that a glycosylation deficient Aspergillus nidulans mutant (BWB26A) impaired in DPMS activity is defective in the production of glucoamylase and invertase, the major secretory glycoproteins. Overexpression in the mu- tant cells of the yeast DPM1 gene increased the secretion of primarily O-mannosylated glucoamylase and N-glycosylated invertase; however, in the transformed strain, the secreted proteins accumulated in the periplasmic space. Electron microscopy of the transformed strain revealed changes in the ultrastructure connected with the secretory pathway.

\section{MATERIALS AND METHODS}

We used A. nidulans 2.1, a Glasgow wild type strain, and BWB26A, a glycosylation deficient mutant (Table 1). The mutant was cotransformed with the yeast DPM1 gene fused under the $A$. nidulans gpdA gene promoter (glyceraldehyde-3 phosphate dehydrogenase) and trp $C$ (indole-3-glycerol phosphate synthase) terminator, using pAN52-1NotI plasmid (NCBI accession number Z32697). The complete coding sequence of the S. cerevisiae DPM1 gene was amplified by PCR, using the Expand High Fidelity PCR System (Boehringer Mannheim, Germany). The primers DPM1s (5' AGC ATC GAA TAC TCT GTT ATC GTT 3') and DPM1r (5' TTA AAA GAC CAA ATG GTA TAG CTG 3') were used for gene amplification. The pAN521N plasmid was cut between the promoter and the terminator with BamHI, the sticky ends were blunted with mung bean nuclease (Promega) and the PCR product was ligated with the plasmid. The pHELP1 plasmid with the $\arg B$ marker gene was used as a partner in cotransformation (Gems et al., 1991; Gems \& Clutterbuck, 1993). Cotransformants were selected for arginine prototrophy, and stable transformants were isolated by three rounds from selective to nonselective medium.

Cultivation. Aspergillus was cultivated at $37^{\circ} \mathrm{C}$ on a rotary shaker at 250 r.p.m. in 2 litre Erlenmayer shake flasks containing 1 litre of AMM (Aspergillus Minimal Medium) containing $6 \mathrm{~g} \mathrm{NaNO}, 0.52 \mathrm{~g} \mathrm{MgSO}_{4} \times$ $7 \mathrm{H}_{2} \mathrm{O}, 0.52 \mathrm{~g} \mathrm{KCl}, 1.59 \mathrm{~g} \mathrm{KH}{ }_{2} \mathrm{PO}_{4} \times 7 \mathrm{H}_{2} \mathrm{O}, 25$ 
$\mathrm{mg} \mathrm{FeSO}_{4} \times 7 \mathrm{H}_{2} \mathrm{O}, 6.2 \mathrm{mg} \mathrm{ZnSO}_{4} \times 7 \mathrm{H}_{2} \mathrm{O}$, at $\mathrm{pH}$ 6.5. The carbon source varied according to the requirements of the experiment (1\% glucose, sucrose or maltodextrin) (Pontercorvo et al., 1953).

Molecular biology methods. Chromosomal DNA was isolated from $A$. nidulans by acid guanidinium thiocyanate-phenol-chloroform extraction, as described previously (Gruber et al.,1990). Total RNA was isolated by the single-step method of Chomczynski \& Sacchi (1987). Other molecular biology techniques were performed according to standard protocols (Sambrook et al., 1989).

Membrane preparation. Aspergillus mycelium was harvested by filtration, washed with water and suspended in $50 \mathrm{mM}$ Tris $/ \mathrm{HCl}, \mathrm{pH}$ 7.4, containing $15 \mathrm{mM} \mathrm{MgCl}_{2}$ and $9 \mathrm{mM}$ $\beta$-mercaptoethanol. Cells were homogenised in a Beadbeater with glass beads $(0.5 \mathrm{~mm})$ and the homogenate was centrifuged at 5000 $\times \boldsymbol{g}$ for $10 \mathrm{~min}$ to remove cell debris and unbroken cells. The supernatant was centrifuged at $100000 \times \boldsymbol{g}$ for $1 \mathrm{~h}$. The membrane pellet was homogenised in $50 \mathrm{mM}$ Tris $/ \mathrm{HCl}$, pH 7.4, containing $3.5 \mathrm{mM} \mathrm{MgCl}_{2}$ and $6 \mathrm{mM}$ $\beta$-mercaptoethanol, and used as the source of enzyme. The whole procedure was performed at $4^{\circ} \mathrm{C}$ (Pless \& Palamarczyk, 1987).

DPMS activity. The enzyme activity was assayed in membrane fraction by incubation of $100 \mu \mathrm{g}$ of membrane proteins with GDP $\left[{ }^{14} \mathrm{C}\right] \mathrm{Man}$ (specific activity $288 \mathrm{Ci} / \mathrm{mol}$; (Amersham)) and $5 \mathrm{ng}$ of dolichylphosphate (DolP), according to Kruszewska et al. (1990; 2000).

In vitro phosphorylation of the membrane proteins was performed with $0.2 \mathrm{mM}$ ATP and 25 units of the catalytic subunit of cAMP dependent protein kinase (Sigma), as described by Kruszewska et al. (1991). Subsequently, dolichylphosphate mannose (DPM) synthesis catalysed by phosphorylated protein was determined as described above.

Protease activity assay. The proteolytic activity in culture filtrates was assayed according to the azocasein method (Lovrien et al., 1985). One unit of proteolytic activity was expressed as an increase in absorbance of reaction mixture at $366 \mathrm{~nm}$ in $1 \mathrm{~min}$ per $1 \mathrm{ml}$.

Invertase induction and activity. A. nidulans strains were grown in $300 \mathrm{ml}$ Erlenmayer shake flask containing $15 \mathrm{ml}$ of AMM medium with $1 \%(\mathrm{w} / \mathrm{v})$ glucose. After $24 \mathrm{~h}$, the mycelium was harvested by centrifugation at $2000 \times \boldsymbol{g}$ for $10 \mathrm{~min}$, washed twice with $10 \mathrm{ml}$ of AMM medium without a carbon source, transferred to $300 \mathrm{ml}$ conical flasks containing $15 \mathrm{ml}$ AMM with $2 \%(\mathrm{w} / \mathrm{v})$ sucrose and incubated for 3, 6, 24 and $48 \mathrm{~h}$. After induction, the mycelium was centrifuged at $2000 \times \mathrm{g}$ for $15 \mathrm{~min}$ at $4^{\circ} \mathrm{C}$. The culture medium was dialysed overnight at $4^{\circ} \mathrm{C}$ against distilled water and the activity of secreted invertase was assayed.

The mycelium was washed with $10 \mathrm{ml}$ sterile distilled water, transferred to a sterile Erlenmayer shake flask, treated with $5 \mathrm{ml}$ of a solution of lytic enzymes containing $5 \mathrm{mg} / \mathrm{ml}$ Novozyme, $2.5 \mathrm{mg} / \mathrm{ml}$ lyticase, $0.6 \mathrm{M} \mathrm{KCl}, 10$ $\mathrm{mM}$ phosphate buffer, $\mathrm{pH}$ 6.0, and incubated with shaking at $37^{\circ} \mathrm{C}$ for $2 \mathrm{~h}$. Cell debris was removed by vacuum filtration through a Schott P2 sintered glass funnel, and protoplasts were recovered from the filtrate by the centrifugation at $2000 \times \boldsymbol{g}$ for $10 \mathrm{~min}$. The filtrate was dialysed against distilled water overnight at $4^{\circ} \mathrm{C}$ and the activity of invertase released from the periplasmic space was determined.

The protoplasts were resuspended in $10 \mathrm{ml}$ $0.6 \mathrm{M} \mathrm{KCl}$ and centrifuged at $2000 \times \mathbf{g}$ for 10 min. The pellet was resuspended in $10 \mathrm{ml}$ of $50 \mathrm{mM}$ Tris/HCl buffer, $\mathrm{pH}$ 7.4, containing 15 $\mathrm{mM} \mathrm{MgCl}_{2}$ and $9 \mathrm{mM} \beta$-mercaptoethanol, and homogenised with glass beads (diameter 0.5 $\mathrm{mm}$ ) in a Beadbeater for $20 \mathrm{~s}$. The activity of intracellular invertase was assayed in the homogenate following overnight dialysis against water at $4^{\circ} \mathrm{C}$ (Vainstein \& Peberdy, 1991).

Invertase activity was determined by the release of reducing sugars from sucrose used as a substrate at $\mathrm{pH} 5.0$ at $30^{\circ} \mathrm{C}$. (One unit of 
invertase liberated $1 \mu$ mole of reducing sugar per $1 \mathrm{~min}$ at $30^{\circ} \mathrm{C}$ ) (Miller, 1959).

Assay of invertase activity in polyacrylamide gel. All samples from the preceding section were taken to dryness, dissolved in $2 \times$ electrophoresis sample buffer (125 mM Tris/HCl buffer, $\mathrm{pH}$ 6.8, 20\% glycerol, 4\% SDS and bromophenol blue) and electrophoresed in $7.5 \%$ polyacrylamide gel. Immediately afterwards, the gel was incubated in $2.5 \%$ Triton X-100 at room temperature for $1 \mathrm{~h}$, washed twice with distilled water, incubated in $0.1 \mathrm{M}$ sucrose in $0.1 \mathrm{M}$ sodium acetate buffer, $\mathrm{pH} 5.0$, at $30^{\circ} \mathrm{C}$, washed again with distilled water, treated with $0.1 \mathrm{M}$ iodoacetamide for $5 \mathrm{~min}$ at room temperature and washed. Subsequently, the gel was incubated in a freshly prepared solution of $0.2 \%$ 2,3,5-triphenyltetrazolium chloride mono- hexokinase diagnostic kit according to the standard protocol (Sigma 115A). One unit of glucoamylase released $1 \mu$ mole of glucose per $1 \mathrm{~min}$ at $30^{\circ} \mathrm{C}$.

Protein determination. Protein was determined by the method of Lowry et al. (1951).

Quantitation of fungal dry weight. Fungal dry weight was quantified by filtering the culture through a coarse $\left(\mathrm{G}_{1}\right.$ grade) sinter funnel, washing the fungal material with a threefold volume of tap water and drying to a constant weight.

Electron microscopy. After $24 \mathrm{~h}$ of induction of invertase secretion, the mycelium was collected by centrifugation at $2000 \times \mathbf{g}$ for $10 \mathrm{~min}$ and processed for electron microscopy as described previously (Kurzątkowski et al., 1991). Ultrathin sections were examined under a JEM100C transmission

Table 1. A. nidulans strains used in the experiments.

\begin{tabular}{ll}
\hline Strain & Phenotype \\
\hline Wild type 2.1 & prototrophic strain \\
Mutant strain BWB26A & pabaA1, biA1, gcnA95(glcA), argB2 \\
26A-ULJK00/9 BWB26A transformed with $D P M 1$ gene & pabaA1, biA1, gcnA95(glcA) \\
\hline
\end{tabular}

2.1 and BWB26A strains were obtained from Dr. Brian W. Bainbridge (Kings College, London, U.K.); pabaA1, para-aminobenzoic acid; biA1, biotin; argB2, arginine; glcA, $1 \%$ glucosamine required for growth at $45^{\circ} \mathrm{C}$.

hydrate in $1 \mathrm{M} \mathrm{NaOH}$, heated in a boiling water bath for 1-2 min, then washed with distilled water, fixed in $7.5 \%$ acetic acid for 30 min and dried under vacuum.

Glucoamylase activity. Aspergillus was grown in AMM medium supplemented with $1 \%(\mathrm{w} / \mathrm{v})$ maltodextrin. Glucoamylase activity was determined as described by Yamasaki et al. (1977). Samples (culture medium, suspension of protoplasts or cell free extract) of $100 \mu \mathrm{l}$ were incubated for $60 \mathrm{~min}$ at $30^{\circ} \mathrm{C}$ in $0.2 \%$ maltose in $0.5 \mathrm{M}$ sodium acetate buffer, $\mathrm{pH}$ 5.3. The reaction was stopped by heating in a boiling water bath for $5 \mathrm{~min}$, and glucose concentration was measured using the Sigma electron microscope (JEOL Ltd., Tokyo, Japan) at $80 \mathrm{kV}$.

\section{RESULTS}

\section{Overexpression of $S$. cerevisiae DPM1 gene in $A$. nidulans mutant}

Previous results (Kruszewska et al.,1999) indicated that protein secretion in the filamentous fungus $T$. reesei could be upregulated by overexpression of the yeast DPM1 gene encoding DPMS. To unravel the link between DPMS involved in protein O-mannosylation and protein secretion, we overexpressed the 
yeast gene in an $A$. nidulans mutant impaired in DPMS activity. To this end, DPM1 was fused under the $A$. nidulans gpdA gene promoter (glyceraldehyde-3-phosphate dehydrogenase) and $\operatorname{trp} C$ (indole-3-glycerol-phosphate synthase) terminator. The resultant plasmid was introduced into the A. nidulans BWB26A glycosylation deficient mutant by cotransformation with pHELP1 containing the $\arg B$ marker, and prototrophic transformants were selected and screened by Southern blotting for the presence of the DPM1 gene. One stable transformant, 26A-ULJK00/9, found among a hundred of isolates, was analysed by Northern blotting for the level of DPM1 expression (Fig. 1). A high level of DPM1 transcript was observed in the total RNA from the 26A-ULJK00/9 strain. This is in agreement with the DPMS activity measured in the

\section{A-ULJK00/9 BWB26A}

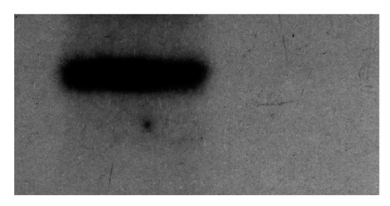

S. cerevisiae DPMI

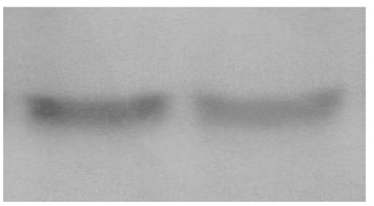

A. nidulans actin

Figure 1. Northern blot analysis of $A$. nidulans BWB26A DPM1 transformant 26A-ULJK00/9.

Total RNA ( $20 \mu \mathrm{g}$ ) from the control strain, BWB26A, and from the transformant were loaded onto the gel, blotted and probed with the 0.6-kb BanII fragment of the $S$. cerevisiae DPM1 gene. Loading controls were hybridised with PCR fragment of $A$. nidulans $\gamma$-actin gene.

microsomal fraction of 26A-ULJK00/9 in comparison to the parental BWB26A strain (Table 2). Expression of the yeast DPM1 gene elevated the activity of the encoded enzyme up to $176 \%$ of that of the BWB26A mutant, but it still remained lower than that in the wild type 2.1 strain. We found also that in vitro phosphorylation of membrane fraction proteins enhanced the DPMS activity. The low activity in the mutant BWB26A strain was stimulated only up to $143 \%$ that of the nonphosphorylated enzyme, whereas an over threefold higher activity was obtained after membrane protein phosphorylation for the transformed strain. It is worth noting that a similar three-fold increase in DPMS activity was observed in phosphorylated membranes from the wild type strain.

\section{Protein secretion and cell ultrastructure}

Overexpression of the DPM1 gene in T. reesei resulted in a seven-fold higher secretion of protein. In contrast, in A. nidulans bearing the yeast gene we did not observe any significant increase in protein secretion to the growth medium. The assay was repeated in the growth conditions used for glucoamylase (Fig. 2A) and, also for invertase (Fig. 2B) induction. In neither case there was an effect on protein secretion to the growth
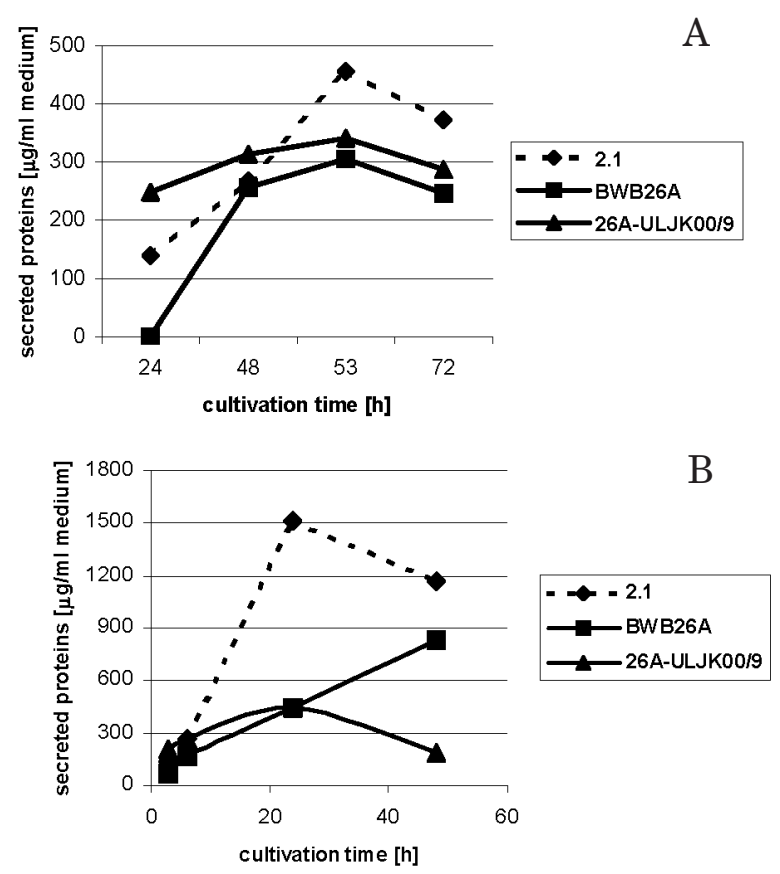

Figure 2. Concentration of secreted proteins in cultivation medium from $A$. nidulans strains grown in conditions inducing glucoamylase (A) and invertase (B).

The data are means of five independent cultivations. 


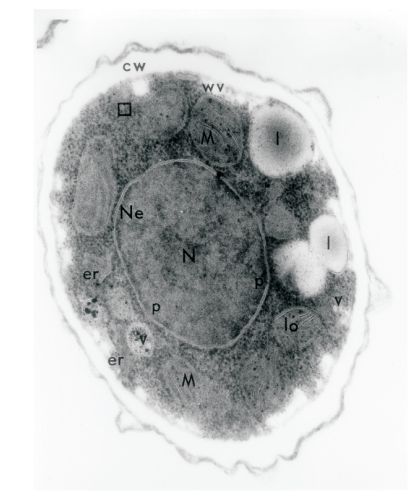

A

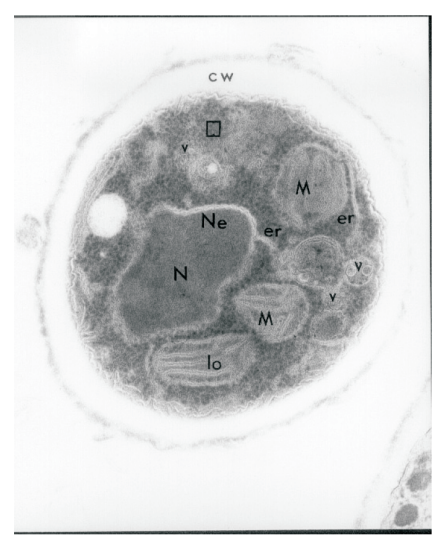

B

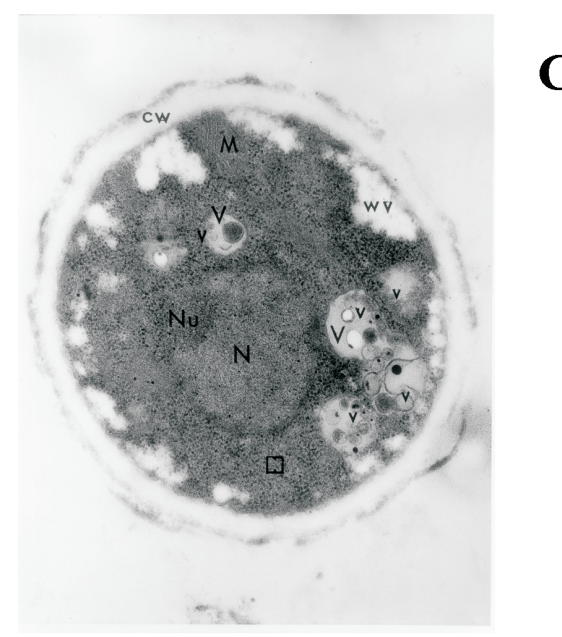

Figure 3. Effect of DPM1 overexpression on cellular ultrastructure of A. nidulans.

Ultrathin sections from: wild type strain 2.1 (A), magnification $47600 \times$; mutant BWB26A (B), magnification $51800 \times$; transformed strain 26A-ULJK00/9 (C), magnification $32500 \times$. CW, cell wall; $\mathrm{N}$, nucleus; $\mathrm{Ne}$, nuclear envelope; $\mathrm{P}$, nuclear pores; $\mathrm{M}$, mitochondria; LO, longitudinally sectioned tubular cristae of mitochondrion; ER, endoplasmic reticulum; L, lipid bodies; $\mathrm{V}$, secretory vesicles; WV, wall vesicles; square, ribosomes. medium. However, since overexpression of the yeast gene in $T$. reesei also altered the structure of the cell wall, we examined if similar changes occurred in A. nidulans (Fig. 3).

Electron microscopy revealed substantial changes in the cells of the 26A-ULJK00/9 strain in comparison to the untransformed mutant. The differences concerned the number of vacuoles and secretory vesicles, which increased twice after transformation (Table 3). This result might suggest changes in the secretory machinery, and thus inspired us to study the process in greater detail. Having in mind that the cell wall was not altered in the transformed $A$. nidulans strain and could constitute a barrier to protein movement, we studied protein secretion to the periplasmic space of the fungal cells. To choose the optimal period of cultivation for enzymatic assays, we looked for the growth phase with the lowest protease activity. The activity of proteases in the cell free extract was assayed after $24,48,53$ and $72 \mathrm{~h}$ of cultivation, with the lowest activity appearing after $24 \mathrm{~h}$ and, importantly, at almost the same level for the three strains (Fig. 4A). Subsequently, we cultivated the A. nidulans 2.1, BWB26A and 26A-ULJK00/9 strains in conditions inducing invertase and glucoamylase expression, and assayed their activities in the medium, in the periplasmic space and inside the cells. The wild type strain 2.1 exhibited glucoamylase activity in every compartment (Fig. 5). The highest activity was observed in the medium and inside the cells, while that in the periplasmic space was lower by over $50 \%$. In the mutant, a very low enzyme activity was detected in the periplasmic space and the growth medium. This distribution changed after transformation with the DPM1 gene. Elevated glucoamylase activity appeared in the periplasmic space with some still present within the protoplasts, suggesting that the cell wall may present a barrier reducing protein secretion. At the same time, in all the strains the highest activity of proteases was detected in the periplasmic space (Fig. 4B). 
Table 2. DPMS activity in microsomal fractions from different strains of $A$. nidulans, with and without protein phosphorylation by cAMP dependent protein kinase.

The data presented are means of five parallel cultures.

\begin{tabular}{llll}
\hline Conditions & \multicolumn{4}{l}{ DPMS activity [pmol/mg protein per 5 min.] } \\
\hline & 2.1 & BWB26A & 26A-ULJK00/9 \\
\cline { 2 - 4 } - protein kinase (control) & 140 & 51.3 & 90.7 \\
+ protein kinase & 469 & 73.4 & 296.5 \\
\hline
\end{tabular}

A

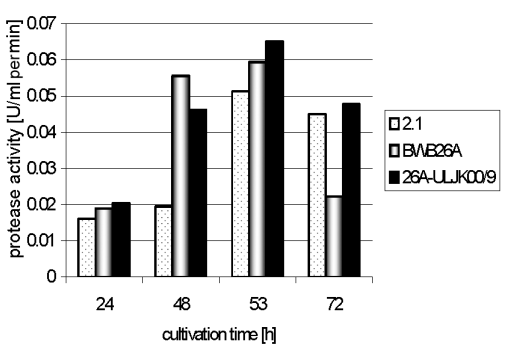

B

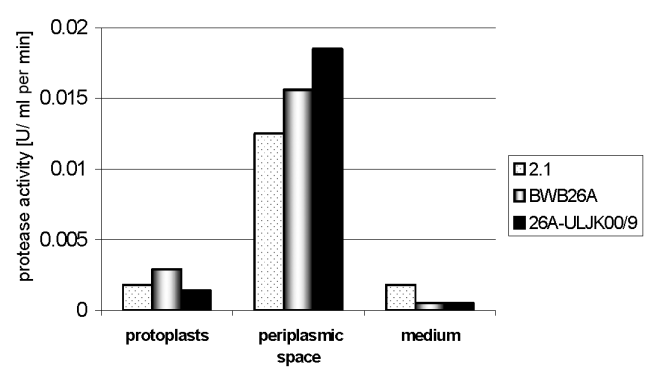

Figure 4. (A) Protease activity in cell free extracts of $A$. nidulans strains cultivated in AMM medium supplemented with maltodextrose. (B) Protease activity in $A$. nidulans cells, in the periplasmic space and in the maltodextrose AMM growth medium after $24 \mathrm{~h}$ of cultivation.

The data are means of five independent experiments.

For a more complete picture of protein secretion in the strain overexpressing DPM1, we chose another enzyme, the N-glycosylated invertase. Synthesis of invertase was induced by growing in a sucrose medium for 3, 6, 24 and $48 \mathrm{~h}$. Total invertase activity in the DPM1 transformed strain was compared to the parental BWB26A and wild type 2.1 strains. In contrast to the 26A-ULJK00/9 strain, where the activity appeared after $6 \mathrm{~h}$ of induction and after $24 \mathrm{~h}$ reached a 28 -fold higher level

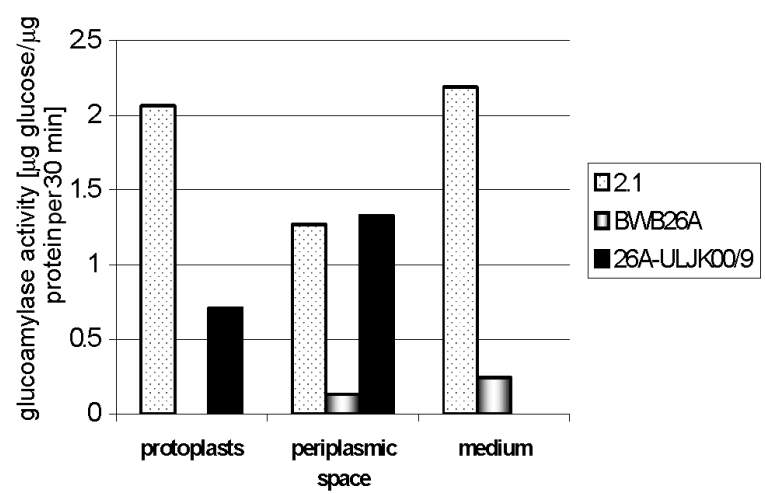

Figure 5. Glucoamylase activity in A. nidulans cells, in the periplasmic space and in the medium after $24 \mathrm{~h}$ of cultivation.

The data are means of five independent experiments.

than in the parental strain, both control strains revealed only very weak total enzyme activity (Fig. 6). Nearly all the enzyme was found in the periplasmic space of the transformed cells (Fig. 7). When analysed in an SDS gel, invertase obtained for protoplasts, from the periplasmic space and from the growth medium exhibited differences in the level of glycosylation. The less glycosylated forms were mostly retained in the cells (Fig. 8). More glycosylated invertase molecules easily passed through the secretory pathway and appeared in the medium, whereas the intermediate glycoforms were found mostly in the periplasmic space.

\section{DISCUSSION}

The secretory abilities of filamentous fungi such as Aspergillus or Trichoderma are being 
Table 3. Ultrastructural differences in A. nidulans overexpressing the yeast DPM1 gene, 26A-ULJK00/9, and two control strains, the wild type, 2.1, and the mutant BWB26A.

\begin{tabular}{llll}
\hline \multicolumn{4}{c}{ No. of organelles/100 cellular sections } \\
\hline Organelle & Strains & BWB26A & 26A-ULJK00/9 \\
\hline Nucleus & 2.1 & 0.9 & 0.8 \\
Mitochondria & 1 & 4.4 & 4.7 \\
Vacuoles & 5.14 & 0.96 & 2.0 \\
Secretory vesicles & 0.54 & 4.0 & 7.3 \\
\hline
\end{tabular}

carefully scrutinised with the view of their possible applicability in biotechnology. Every factor recognised as a potential stimulant of protein secretion appears to be highly valu- able for biotechnological production of biologically active proteins. Stimulation of O-glycosylation by overexpression of the yeast $D P M 1$ gene in $T$. reesei offered promise of activating

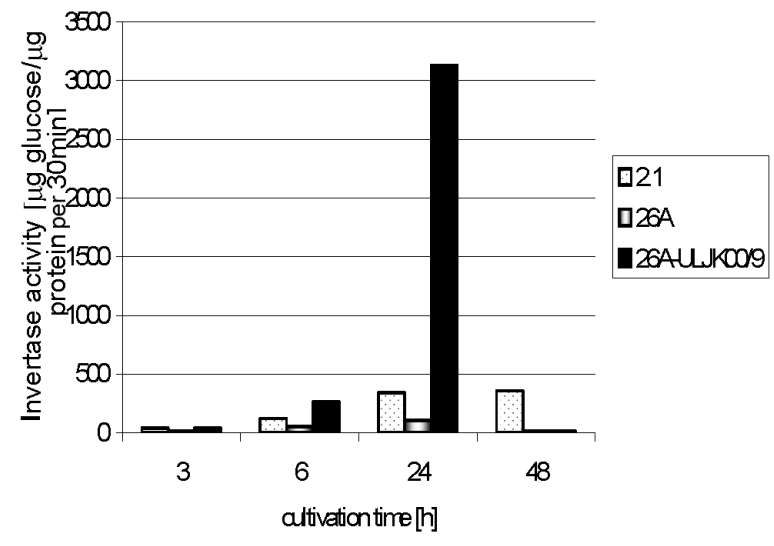

Figure 6. Total invertase activity in A. nidulans cell free extracts after different periods of cultivation.

The data are means of five independent experiments.

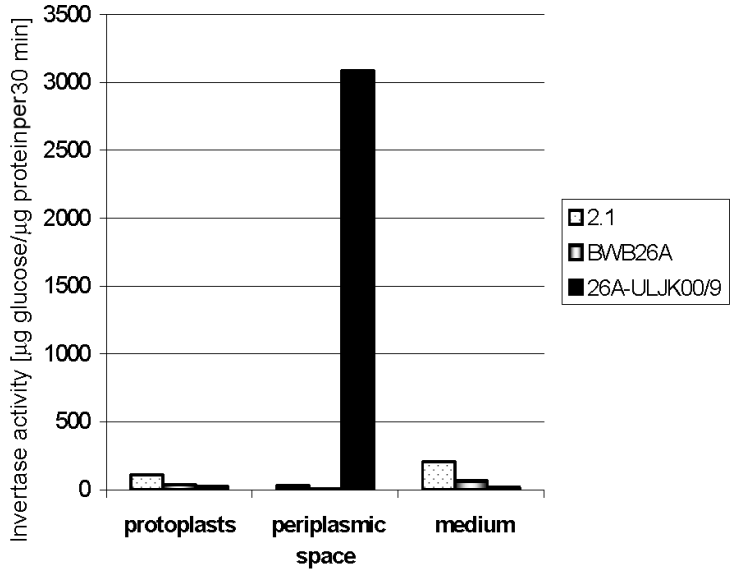

Figure 7. Invertase activity in $A$. nidulans cells, the periplasmic space and the medium after $24 \mathrm{~h}$ of cultivation.

The data are means of five independent experiments.

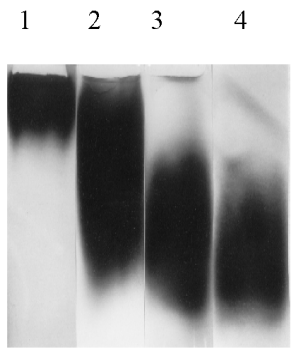

2.1

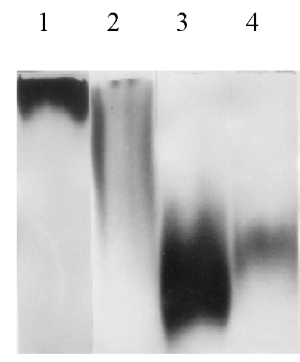

BWB26A

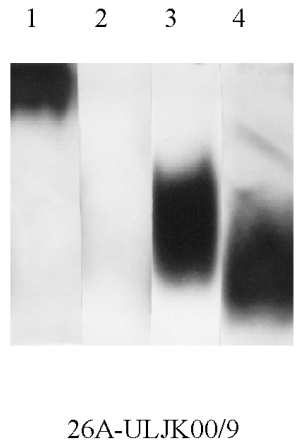

Figure 8. Invertase activity in the wild strain 2.1, mutant BWB26A and transformed strain 26A-ULJK00/9 in the medium (2), the periplasmic space (3) and the cells (4) in comparison to the S. cerevisiae standard (1). 
protein production and/or secretion (Kruszewska et al., 1999). The O-glycosylation stimulation resulted in the seven-fold higher secretion of proteins being glycosylated to the wild type level. However, changes in morphology of the transformed cells complicated the correlation between glycosylation and protein secretion. In this study, overexpression of the $D P M 1$ gene in $A$. nidulans mutant cells caused elevation of DPMS activity, although to a level still below that in the wild type strain. This effect could be explained by the heterologous nature of the protein activity. It is noteworthy that yeast DPMS belongs to the $S$. cerevisiae group of enzymes with a transmembrane domain at the C-terminus and active without participation of other proteins. For this reason we chose yeast DPM1 for expression in other organisms. Homologous overexpression of the $d p m 1$ gene in $T$. reesei resulted in an increase in DPMI protein level without any effect on DPMS activity (Zakrzewska et al., 2003). In contrast to the $S$. cerevisiae enzyme, DPMS from $T$. reesei belongs to the human group of such enzymes and requires additional subunits for full activity (Kruszewska et al., 2000). Overexpression of one subunit turned out to be insufficient to induce the expression of the other subunits, and the activity of DPMS remained unchanged. The $A$. nidulans gene encoding DPMS has not been cloned yet, and only by analogy to $T$. reesei we can presume that it belongs to the human group of these enzymes.

In this study we expected changes in the morphology of $A$. nidulans cells upon transformation, especially in view of the increased cell wall permeability observed previously for the $T$. reesei transformants (Kruszewska et al., 1999; Lenart et al., 2003). In A. nidulans significant changes in ultrastructure were found in the secretory apparatus and concerned the secretory vesicles. Although transport of secretory proteins seemed to be intensified, the proteins stayed trapped within the periplasmic space. Invertase observed in the gel revealed limited glycosylation of the en- zyme retained in the cells and periplasmic space in comparison to that in the medium of the wild type strain 2.1. Therefore, the partially blocked secretion could be due to limited glycosylation or to the impermeability of the cell wall. On the other hand, the $H$. polymorpha opu24 mutant secreted unglycosylated invertase more efficiently than the parental strain secreted the glycosylated form (Agaphonov et al., 2001). This could be explained by the key role in secretion played by the morphologically altered cell wall. The $H$. polymorpha mutant cells were shown to be sensitive to an osmotically destabilising detergent, SDS, and increasingly susceptible to zymolyase. Characterisation of $T$. reesei DPM1 transformants revealed that even the more permeable cell wall still constituted a barrier to secretion (Kruszewska and Palamarczyk, unpublished). Studies on $A$. nidualns and $H$. polymorpha showed that limited $\mathrm{N}$-glycosylation did not hinder secretion of $\mathrm{N}$-glycosylated proteins, but partially blocked O-glycosylation could do so. Secretion of chitinase in the $H$. polymorpha mutant was strongly inhibited when the enzyme was less glycosylated. The trace secretion of $\mathrm{O}$ - and $\mathrm{N}$-glycosylated glucoamylase in the $A$. nidulans mutant was probably unrelated to the defect in N-glycosylation.

Comparison of the effect of glycosylation on protein secretion in different organisms presents great difficulties. Partial inhibition of glycosylation in A. nidulans blocked the production and secretion of invertase and glucoamylase, whereas in the $H$. polymorpha mutants only the O-glycosylated chitinase was negatively affected.

Stimulation of O-glycosylation in T. reesei and $A$. nidulans elevated protein secretion; however, in $T$. reesei the proteins were secreted to the medium (Kruszewska et al., 1999) whereas in $A$. nidulans only to the periplasmic space. Varied morphological effects were observed in every organism with altered glycosylation. Our study showed that upregulation of glycosylation processes could 
help in effective protein production and secretion, but the correlation between glycosylation and possible changes in cell morphology requires further studies.

\section{R E F E R E N C E S}

Agaphonov MO, Packeiser AN, Chechenova MB, Choi E, Ter-Avanesyan MD. (2001) Mutation of the homologue of GDP-mannose pyrophosphorylase alters cell wall structure, protein glycosylation and secretion in Hansenula polymorpha. Yeast.; 18: 391-402.

Chomczynski P, Sacchi N. (1987) Single-step method of RNA isolation by acid guanidininium thiocyanate-phenol-chloroform extraction. Anal Biochem.; 162: 156-9.

Gems DH, Clutterbuck AJ. (1993) Co-transformation with autonomously replicating helper plasmids facilitates gene cloning from an Aspergillus nidulans gene library. Curr Genet.; 24: 520-4.

Gems DH, Johnstone IL, Clutterbuck AJ. (1991) An autonomously replicating plasmid transforms Aspergillus nidulans at high frequency. Gene.; 98: 61-7.

Gruber F, Visser GFJ, Kubicek CP, de Graff LH. (1990) The development of heterologous transformation system for the cellulolytic fungus Trichoderma reesei based on a pyrG-negative mutant strain. Curr Gen.; 18: 71-6.

Kruszewska J, Palamarczyk G, Kubicek CP. (1990) Stimulation of exoprotein secretion by choline and Tween 80 in Trichoderma reesei QM 9414 correlates with increased activity of dolichol phosphate mannose synthase. $J$ Gen Microbiol.; 136: 1293-8.

Kruszewska J, Palamarczyk G, Kubicek CP. (1991) Mannosyl-phospho-dolichol synthase from Trichoderma reesei is activated by protein kinase dependent phosphorylation in vitro. FEMS Microbiol Lett.; 80: 81-6.

Kruszewska J, Butterweck AH, Kurzątkowski W, Migdalski A, Kubicek CP, Palamarczyk G. (1999) Overexpression of the Saccharmyces cerevisiae mannosylphosphodolichol synthase - encoding gene in Trichoderma reesei results in an increased level of protein secretion and abnormal cell ultrastructure. Appl Environm Microbiol.; 65: 2382-7.

Kruszewska JS, Saloheimo M, Migdalski A, Orlean P, Penttilä M, Palamarczyk G. (2000) Dolichol phosphate mannose synthase from the filamentous fungus Trichoderma reesei belongs to the human and Schizosaccharomyces pombe class of the enzyme.

Glycobiology.; 10: 983-91.

Kubicek CP, Panda T, Schreferl-Kunar G, Messner R, Gruber F. (1987) O-linked - but not N-linked-glycosylation is necessary for secretion of endoglucanase I and II by Trichoderma reesei. Can J Microbiol.; 33: 698-703.

Kurzątkowski W, Palissa H, Liempt H, Van Doehren H, Von Kleinkauf H, Wolf WP, Kurylowicz W. (1991) Localisation of isopenicillin N synthase in Penicillium chrysogenum PQ 96. Apll Microbiol Biotechnol.; 35: 517-20.

Lenart U, Kruszewska J, Orłowski J, Zdebska E, Laudy A, Kurzątkowski W, Palamarczyk G. (2003) Alteration of Trichoderma reesei cell wall and morphology exerted by overexpression of the yeast dolichyl phosphate mannose synthase gene. II International Conference on Molecular Mechanisms of Fungal Cell Wall Biogenesis. Salamanca, Spain p. 13.

Lovrien RE, Gusek T, Hart B. (1985) Cellulase and protease specific activities of commercially available cellulase preparations. $J$ Appl Biochem.; 7: 258-72.

Lowry OH, Rosebrough NJ, Farr AL, Randall RJ. (1951) Protein measurement with the Folin phenol reagent. J Biol Chem.; 193: 265-75.

Miller GL. (1959) Use of dinitrosalicylic acid reagent for determination of reducing sugars. Anal Chem.; 31: 426-8.

Pless DD, Palamarczyk G. (1987) Comparison of polyprenol derivatives in yeast glycosyl transfer reactions. Biochem Biophys Acta.; 529: 21-8. 
Pontercorvo G, Roper JA, Hemmons LM, MacDonald KD, Buffon AWJ. (1953) The genetics of Aspergillus nidulans. Adv Genet.; 5: 141-238.

Sambrook J, Fritsch EF, Maniatis T. (1989) Molecular Cloning: a Laboratory Manual, 2nd edn, vol 1, pp 7.37-7.52. Cold Spring Harbor Laboratory, Cold Spring Harbor, N.Y.

Vainstein LM, Peberdy J. (1991) Regulation of invertase in Aspergillus nidulans: the effect of different carbon sources. $J$ Gen

Microbiol.; 137: 315-51.
Yamasaki Y, Suzuki Y, Ozawa J. (1977) Purification and properties of two forms of glucoamylase from Penicillum oxalicum. Agr Biol Chem.; 41: 755-62.

Zakrzewska A, Palamarczyk G, Krotkiewski H, Zdebska E, Saloheimo M, Penttilä M, Kruszewska JS. (2003) Overexpression of the gene encoding GTP-mannose-1-phosphate guanyltransferase, $m p g 1$, increases cellular GDP-mannose levels and protein mannosylation in Trichoderma reesei. Appl Environm Microbiol.; 69: 4383-9. 